\title{
Residential Segregation and Socioeconomic Integration of Visible minorities in Canada
}

T.R.Balakrishnan and Paul Maxim Department of Sociology

The University of Western Ontario

London, Ontario, Canada

IUSSP Conference - July 23, 2005

Tours, France 


\title{
Residential Segregation and Socioeconomic Integration Of Visible Minorities in Canada
}

\author{
T.R.Balakrishnan and Paul Maxim \\ Population Studies Centre \\ University of Western Ontario
}

\begin{abstract}
Using Census data this paper tests the validity of the spatial assimilation model for the visible minorities in the seven largest Metropolitan Areas of Canada. It shows that residential segregation levels for the four largest visible minority groups remain relatively high during the period 1981-2001. Even while there is assimilation of earlier immigrants the large number of new immigrants in recent years have kept the segregation levels high in the cities. It is found that segregation levels have little relation to the absolute size of the minority group or its city proportion, a rather surprising finding. Further, there seems to be no significant relationship between segregation indices and measures of socioeconomic achievement such as education, occupation or income. Visible minority immigrants have much higher level of educational attainment than the other groups. However they are under- represented in managerial occupations and have significantly lower incomes. The Chinese and South Asians seem to do better than the Blacks and much better than the Filipinos. Many visible minority neighbourhoods in Canada are not situated in the city core and do not show the urban blight often associated with Black neighbourhoods in the United States, and raises the question that some amount of spatial concentration and social integration can go together. Some credit for this may be attributable to the Multiculturalism policies of Canadian government.
\end{abstract}




\section{Residential Segregation and Socioeconomic Integration of Visible minorities in Canada}

\section{Introduction}

In 2001, almost 4 million people in Canada were identified as visible minorities, about 13.4 percent of the total population. Given the present immigration trends, this proportion is expected to increase further in the future. For example, more than half of the immigrants since 1980 were the so-called 'visible minorities' of Blacks, South Asians, Chinese, Filipinos and Latin and Central Americans. These immigrants have their own distinct patterns of settlement. Most of them go to the metropolitan areas, especially the three gateway cities of Toronto, Montreal and Vancouver. In Toronto, the proportion of visible minorities was 38.67 percent in 2001 and in Vancouver, 38.71 percent (Statistics Canada 2003). They are further found to be concentrated in certain areas of the city. Visible minorities show greater concentrations in the cities and these concentrations persist over time as compared to the European groups. Parallel to the studies on residential segregation, there has been considerable interest on how well the new immigrants do economically in their new country of residence. While some studies have found that immigrants do quite well with longer duration of stay in Canada, some recent research show that their relative position has slipped in the past decade, especially among the new entrants (Baker and Benjamin 1994; Bloom, Grenier and Gunderson 1995; Frenette and Morissette 2005). Whether spatial residential patterns have any relation to socioeconomic achievement of an ethnic group in contemporary urban Canada is the focus of this study.

The Spatial assimilation model, derived from human ecology, has implied that new arrivals to metropolitan areas will be at the bottom of the socioeconomic ladder and are most likely to be concentrated in the poorer sections of the city (Burgess 1925; Lieberson 1963; Massey and Duncan 1985). Moreover, a lack of official language facility and social networks, occupational skills, and economic resources may make the immigrants settle in ethnic enclaves. Discrimination against certain immigrant groups in housing and labour markets may also force them into specific areas of the city, and thus increase their spatial concentration and segregation from specific groups such as the British or other European origin groups in Canada (Fong and Wilkes 1999). Thus, involuntary factors such as one's social class and social distance determine residential location. As their social position improves, the immigrants are able to disperse to more desirable neighbourhoods. The model assumes that ethnic segregation is essentially social class segregation and should decrease with the 
social mobility of the group. With increased assimilation in the country's occupational and industrial structure, ethnic residential segregation should decrease (Balakrishnan 2000; Balakrishnan and Kralt 1987). This is basically a human ecological perspective that emphasizes the economic dimensions and puts less importance on the cultural factors in settlement patterns. However, it is well documented that social class alone cannot explain all of the observed ethnic and racial segregation (Darroach and Marston 1971; Balakrishnan and Kralt 1987).

On the other hand, persons of same ethnic ancestry may choose to live in proximity so that social interaction can be maximized and group norms and values can be maintained (Driedger and Church 1974; Balakrishnan and Selvanathan 1990). Size and concentration may provide some advantages. Ethnic clubs, churches, language newspapers, and speciality stores require a threshold population to be successful. Ironically, the greater the self-identity of an ethnic group, the more likely they will be residentially segregated. Canada’s “multiculturalism” policy recognizes these various forces and is based on the idea that the best way of integrating recent immigrant groups into the Canadian social system is to preserve and enhance the multicultural heritage of Canadians while working to achieve the equality of all Canadians in the country's economic, social, cultural and political life.

Contrary to most discrimination models, the assumption that greater spatial concentration and resultant segregation reveals a lack of integration into the wider society can be questioned. Some recent research studies show that while residential segregation continues to be high, many groups such as the Chinese and South Asians in Canadian cities have improved their occupational status with a longer duration of stay in Canada (Balakrishnan and Hou.1999). It may very well be that many minority group members are able to live in ethnic neighbourhoods and still do well economically. One determining factor may be that recent immigrants have higher education and job skills at the time of their immigration to Canada. Government policies on job and language training and job placement may help their integration. At the same time, some groups such as Blacks and Aboriginal peoples are not only segregated but socioeconomically more disadvantaged. The main question is whether the relationship between residential segregation and social integration is weakening in Canada. In other words, is the spatial assimilation model less relevant than in the past?

The test of the spatial assimilation model is further complicated in times of mass immigration as is the case of visible minorities in Canada in recent decades. Rapid growth of ethnic and racial minorities through immigration can increase their concentration and segregation from the majority 
groups. For example visible minority neighbourhoods have increased rapidly in the gateway cities of Toronto, Montreal and Vancouver in the past two decades. Defining a "visible minority neighbourhood" as a census tract where at least $30 \%$ of its population is from a particular visible minority, one study found that the numbers of such neighbourhoods in the three cities increased from 6 in 1981 to 77 in 1991 and to 254 in 2001 (Hou and Picot 2004). While the older immigrants move from ethnic neighbourhoods, new immigrants move into the same neighbourhoods keeping the concentration high (Hou 2004). Statistical reasoning would imply that greater numbers of an ethnic group will increase interaction among them and decrease such interaction with members outside the group. Decrease in segregation among the older immigrants may be offset by the segregation of recent immigrants. This paper examines residential segregation among the various visible minorities in Canada in 2001 in the seven largest metropolitan areas of Canada and its relation to their socioeconomic integration. It tests the hypothesis that the relationship between spatial residential patterns and socioeconomic achievement has weakened over time. In other words, although ethnic neighbourhoods promote the retention of ethnic identity and culture they need not hamper participation in the labour markets of the wider community.

\section{Data and Research methods}

The data for the study mostly come from the Canadian censuses of 2001. Within the metropolitan areas, census tract data are used to construct segregation indices. Because smaller CMAs (Census Metropolitan Areas) will not contain enough visible minorities and can give unstable indices, we have restricted our analysis to the seven largest CMAs. Moreover, most visible minorities live in these largest CMAs. Census tract data in the CMAs are used to construct residential segregation indices. The selected measure of segregation is the index of dissimilarity showing the differential distribution of two groups. The index is the sum of either the positive or negative differences between the proportional distributions of two populations. The Index of Dissimilarity, measuring evenness, is the most widely used measure and, consequently, facilitates comparability. We examine the indices of dissimilarity between the various minority populations and the rest of the population in each of the CMAs.

To measure socioeconomic integration we select three variables: education, occupation and wage income. For education we compare the educational level of persons aged 15 or over with a university degree in the different minority groups with national figures. A similar analysis is made 
for persons in the higher occupations, namely managerial. The measure for income is the wage income in 2000 of full-time employed persons aged 15 or over in 2001. Measures of socioeconomic achievement are examined in relation to segregation indices to investigate the strength and direction of any perceived correlations.

\section{Residential Segregation of selected visible minorities in 2001}

Segregation indices were calculated for the four largest visible minority groups, namely, Chinese, South Asians, Blacks and Filipinos for seven largest CMAs. Table 1 presents these indices. The table also shows the size of the ethnic minority as well as its size as a percentage of the CMA population, to investigate whether these factors are related to the level of segregation in the city. City population size and ethnic group size are no assurance that segregation will be low. The Chinese have high segregation indices in the three gateway cities of Montreal, Toronto and Vancouver. While Chinese only form 1.54 percent of Montreal's population, they are substantial in Toronto and Vancouver, where they form 8.81 percent and 17.42 percent of the population respectively. Though they have a long history of residence in these cities, they continue to live in Chinese neighbourhoods.

Though the indices do not reach the levels of Black integration in the U.S. cities, which are often around .8 to .9, they are high around .5. Calgary and Edmonton have a fairly high proportion of Chinese around 5 percent, but show lower segregation. The pattern is similar for the South Asians. Toronto and Vancouver, in spite of their large South Asian populations, both in absolute numbers and as city proportions, show moderate to high segregation. Blacks show lower segregation in all the CMAs compared to the other visible minority groups, a pattern very different from that in the United States (Massey and Denton 1987). Filipinos show a great deal of variability. In Montreal, they are highly segregated with an index of .743 and their size is small. In Winnipeg where they form a much larger proportion at 4.55 percent than in any other CMA, their segregation is high at .637. There are considerable differences among the CMAs. But there does not seem to be any systematic relationship between ethnic group size and its level of segregation in the city.

\section{Temporal changes in Residential Segregation}

Comparison of segregation indices over time becomes problematic because of changes in 
the ethnic categories used and, more importantly, due to multiple response. Multiple responses in the Canadian censuses have increased rapidly in recent years. However, in the case of visible minorities, around 90 percent give only a single response and the segregation indices calculated using single response only or total response (single and multiple) are not likely to be too different. This caution is important in the interpretation of the figures in Table 2 which present the residential segregation indices for the four visible minority groups over 1981-2001. The figures for 1981-1991 are based on single response only, while 1996 and 2001 figures are calculated from total responses. Though strictly not comparable, they still serve the purpose of showing the overall trends during the last two decades. The important finding is that the segregation indices show remarkable consistency. They not only persist but may show a slight increase in certain cases. We can make some specific observations. Both for the Chinese and South Asians, the indices for Toronto and Vancouver where most of them live show an increase in segregation. The explanations for this phenomenon can be complex. Two opposing forces affect the segregation levels. The period under study saw heavy immigration of these groups, most of them going to the two CMAs. New immigrants have a greater tendency to go to ethnic enclaves as they are heavily influenced by family and friends residing there. This will result in an increase in the concentration and hence in the correlated segregation indices. At the same time one can expect the older immigrants to move out of the ethnic neighbourhoods to areas less segregated mainly in the affluent suburbs. For the Chinese the index increased from .434 in 1981 to .531 in 2001 Toronto and from .468 in 1981 to .500 in 2001 in Vancouver. For the South Asians the index increased from .390 to .449 in Toronto and from .367 in 1981 to .528 in 2001 in Vancouver. The pattern was less evident in the other CMAs which experienced lower levels of immigrants. The increases in the indices were also not noticeable in the case of Blacks.

\section{Socioeconomic Integration of visible minorities}

We use three variable, education, occupation and income to measure the economic integration. Table 3 presents the percentage of ethnic group 15 and over who have a university degree in each of the seven CMAs and in Canada as a whole. Except for the Blacks, the other visible minorities have much higher levels of education than the national average. Taking the whole Canadian population, 15.4 percent had a university degree or higher education. Among the visible minorities of Chinese, South Asians and Filipinos this proportion is almost double. The selection criteria for recent immigrants assure the high education level of immigrants. Only the Blacks have 
a lower level of 12.7 percent for university graduates. Differences among the CMAs were revealing. The highest educational level is found in Ottawa, where 45.7 percent of the Chinese and 50.1 percent of South Asians 15 years of age or over had a university degree compared to 25.9 percent for this age group in the city for the total population. The occupational structure in Ottawa is heavily influenced by the federal government and the IT sector employing persons with high educational qualifications. Chinese, as a group, have uniformly higher education levels in all the cities considered here in relation to the city average. The same is true for the Filipinos who have much level of higher education, except in Winnipeg, where the proportion with a university degree is only 17.0 percent. In many cities, the Blacks have much lower levels than the city average. In Toronto, where most of the Blacks reside, the proportion of Blacks with a university degree is only 9.2 percent compared to 22.9 percent for the city as a whole. Residential Segregation indices have no obvious relation to educational level. Blacks have a much lower segregation index of .397 in Toronto in 2001 compared to .531 for the Chinese in spite of their lower educational level. Similarly, Filipinos in Montreal have a high educational level of 27.7 percent with university education, but also are highly segregated with an index of .743. Filipinos in Vancouver are highly educated with a proportion of 33.8 with a university degree but are much less segregated residentially with an index of .378.

Employment in higher occupations is often considered as an indication of social mobility in a society. We examine the proportion employed in managerial occupations for the four visible minorities in the selected CMAs in Table 4. In Canada as a whole, 10.4 percent of the labour force is in managerial occupations. Chinese do better than the other visible minorities at 11.8 percent, with South Asians second at 9.1 percent. Both Blacks and Filipinos fare much worse. Their proportion in the managerial occupations is only about half of the national average. Filipinos in spite of their high educational level have the lowest proportion ( 4.6 percent) in managerial occupations. There is considerable variation among the CMAs with Toronto having the highest proportion in managerial occupations at 13.0 percent and Winnipeg the lowest at 9.5 percent. Intercity variations by visible minority groups are striking. In the three gateway cities of Montreal, Toronto and Vancouver, Chinese do better than the South Asians, but in Calgary, Edmonton and Ottawa, the South Asians do better than the Chinese. Filipinos do worse in all the cities compared to other visible minorities. In Winnipeg, where there is the highest concentration of Filipinos, the proportion in managerial occupations is only 2.2 percent. Here again patterns in residential segregation have no discernable 
relationship to occupational patterns.

The income of immigrants in relation to Canadian born has been widely studied as a measure of how well they are integrated into the labour market. While earlier studies have shown that immigrants do improve their income with longer duration of stay in Canada, some recent research has shown that there has been a deterioration especially on entry level earnings (Bloom, Grenier and Gunderson 1995; Frenette and Morissette 2005). Questions as to whether they will ever catch up during their lifetime are raised by some economists (Frenette and Morissette 2005). Our interest is to see whether the income level is related to segregation patterns and how they compare with the educational and occupational achievement examined earlier. The measure of income we have chosen is average employment income of persons 15 and over in 2000 as reported in the 2001 census. Table 5 presents average income in the different CMAs by visible minority status. Since income varies substantially by gender, the data are presented separately for males and females.

Among the males, Chinese and South Asians do much better. The average income of a Chinese male was $\$ 45,379$ compared to the national average of $\$ 49,224$ for a ratio of about .92 and that of a South Asian $\$ 44,197$ at a ratio of .90 . In comparison the Black income is only .78 of the national income and Filipino income is even lower at a ratio of .74.

City comparisons show that in the largest three CMAs the relative income of males in the four visible minority groups is lower than in the other four CMAs. A Chinese male in Montreal or Vancouver earns only three fourths of the city average income. It is only slightly higher in Toronto at 81 percent. In the three major CMAs, the South Asians earn only three fourths of the city average. Blacks who live mostly in Montreal and Toronto earn only two thirds of the city average. The Filipinos fare the worst, making only about two thirds in all the CMAs except in Ottawa where they earn about three fourths of the city average. In the other four CMAs, the visible minorities do better, though still earn below the city averages. Ottawa is the only CMA, where the Chinese and South Asians actually do better than the city average, though only by a small percentage.

Visible minority women seem to do better than visible minority men in terms of relative income, a finding found by other researchers as well (Boyd 1992 ). Chinese women earn as much as the national average for women. South Asian and Black women make about 90 percent of the national average for all women. Filipino women who are at the bottom of the four groups considered here earn about 85 percent of the national average. They are however better than their male counterparts who earn only 74 percent of the national average income for men. Inter city 
comparisons show that the trends for women follow that of the men. There is more gender equality in income in Ottawa compared to the three largest CMAs. Though there seems to be some negative relationship between segregation levels and income, the small numbers of CMAs studied here do not warrant any generalizations.

\section{Conclusions}

Traditional literature on urban segregation suggests that ethnic clustering is primarily a consequence of systematic discrimination and/or poor socioeconomic resources. With increasing social mobility the level of segregation is expected to decline. This has been the case in many cities in the U.S. and elsewhere. This paper shows that this spatial assimilation model does not work well in the Canadian context. Residential segregation persists over time. A comparison of segregation in the major CMAs show that there is considerable variation among them. There does not seem to be any systematic relationship between segregation and socioeconomic achievement measured by such variables as education, occupation and income. Immigrants have high educational achievement except in the case of Blacks. Chinese and South Asians do well in the occupational structure though their educational skills warrant better performance. Blacks and Filipinos do much worse as only a few are in the managerial occupations. In the case of income all the visible minorities do worse than the general population, especially in the large gateway cities.

The weak relationship of segregation to socioeconomic achievement warrants a fresh perspective to segregation research in Canada. Ethnic neighbourhoods in Canada can be found not only in the city core but also in affluent suburbs. One may surmise that cultural factors such as the need to maintain cultural identity, ethnic social institutions, and a distinct way of life may sustain ethnic enclaves. There is evidence that there is a greater acceptance of ethnic diversity in Canada than in other industrialized countries. Intermarriage between white European groups and the visible minorities is increasing, albeit, very slowly. These factors suggest that segregation should decrease over time. However, if the rates of immigration of visible minorities continue at the present levels, segregation indices can be expected to remain high. It is not clear what the impact of Canada's multicultural policies is on segregation levels. These policies emphasize preservation of cultural heritage, yet seem to work well in terms of immigrant integration in the mainstream Canadian Society and the acceptance of Canadian values. Whether they also help sustain high segregation levels and ethnic neighbourhoods is not clear. 


\section{References}

Baker, M. and D.Benjamin. 1994. "The performances of Immigrants in the Canadian Labour Market”, Journal of Labour Economics, 12(3): Pp.369-405

Balakrishnan T.R. 2000. “Residential Segregation and Canada’s Ethnic Groups,” in Kalbach and Kalbach (eds). Perspectives on Ethnicity in Canada. Pp.121-136. Harcourt Canada. Toronto.

Balakrishnan T.R. and John Kralt. 1987. "Segregation of visible minorities in Montreal, Toronto and Vancouver,” in Leo Driedger (ed). Ethnic Canada: Identities and Inequalities. Pp. 138-157. Toronto. Copp Clark Pitman.

Balakrishnan T.R. and Selvanathan K.1990. "Ethnic residential segregation in metropolitan Canada”, in Shiva Halli, Frank Travato and Leo Dreidger (eds). Ethnic Demography. Pp. 399-413. Ottawa. Carleton University Press.

Balakrishnan T.R. and feng Hou. 1999. “Socioeconomic Integration and Spatial residential patterns of immigrant groups in Canada”.Population Research and Policy Review. 18(6).Pp.201-217.

Bloom, D.E.;G.Grenier and M.Gunderson. 1995. “ The changing labour market position of Canadian Immigrants’, Canadian Journal of Economics. 28(4): Pp.987-1005

Boyd, Monica. 1992. “ Gender, visible minority, and immigrant earnings inequality: Reassessing and employment equity premise”. In Victor Satzewich (ed). Deconstructing a Nation: Immigration, Multiculturalism and Racism in 90s Canada. Halifax. Fernwood.

Burgess,E.W.1925.“ The Growth of the city: An Introduction to a research project”, in R.E.Park E.W.Burgess and R.E.McKenzie (eds). The City. Pp.47-62. Chicago .University 
Of Chicago Press.

DarrochA.G. and Marston. W.G. 1971.“ The social class basis of ethnic residential segregation: The Canadian case”. American Journal of Sociology. 77. Pp. 491-510.

Driedger, Leo and Church, Glenn. 1974.”Residential segregation and institutional completeness: A comparison of ethnic minorities”. Canadian Review of Sociology and Anthropology. 11. Pp.30-52.

Frenette. Mark. And Rene Morissette. 2005. "Will They Ever Converge? Earnings of Immigrant and Canadian-born Workers over the Last Two Decades”, International Migration Review.39(1). Pp.228-258

Hou Feng. 2004. “Spatial assimilation of racial minorities under conditions of mass immigration” Canadian Social Trends.

Hou Feng and Garnett Picot. 2004. "Visible minority neighbourhoods in Toronto, Montreal And Vancouver” . Canadian Social Trends. Pp.8-13. Statistics Canada.

Fong Eric and Rima Wilkes. 1999. “An Examination of Spatial Assimilation Model”, International Migration Review 33(3). Pp.594-620.

Lieberson, Stanley. 1963. Ethnic Patterns in American Cities. New York. Free Press.

Massey, Douglas and Denton, Nancy. 1985. "Spatial assimilation as a socioeconomic outcome”. American Sociological Review 50: 94-106.

Massey, Douglas and Denton, Nancy. 1987. “Trends in the Residential Segregation of Blacks, Hispanics and Asians:1970-1980". American Sociological Review 52. Pp.802-25.

Statistics Canada. 2003. Canada’s ethnocultural portrait: The Changing ethnic mosaic. 2001 
Census analysis series. Catalogue no. 96F0030XIE2001008. Ottawa. 
Table 1: Segregation indices of selected ethnic groups in the largest metropolitan areas of Canada-2001.

\begin{tabular}{|c|c|c|c|c|c|c|}
\hline & $\begin{array}{l}\text { Segregation } \\
\text { Index }\end{array}$ & $\begin{array}{r}\text { Size of Ethnic } \\
\text { Group }\end{array}$ & $\begin{array}{r}\% \text { of Ethnic } \\
\text { group } \\
\text { in City }\end{array}$ & $\begin{array}{r}\text { Segregation } \\
\text { Index }\end{array}$ & $\begin{array}{r}\text { Size of Ethnic } \\
\text { Group }\end{array}$ & $\begin{array}{r}\% \text { of ethnic } \\
\text { Group } \\
\text { in City }\end{array}$ \\
\hline & & Chinese & & & Blacks & \\
\hline Montreal & 0.538 & 52,110 & 1.54 & 0.460 & 139,305 & 4.12 \\
\hline Toronto & 0.531 & 409,530 & 8.81 & 0.397 & 310,500 & 6.68 \\
\hline Vancouver & 0.500 & 342,665 & 17.42 & 0.328 & 18,405 & 0.94 \\
\hline Calgary & 0.396 & 51,850 & 5.50 & 0.337 & 13,665 & 1.45 \\
\hline Edmonton & 0.403 & 41,285 & 4.45 & 0.365 & 14,095 & 1.52 \\
\hline Ottawa & 0.439 & 28,810 & 2.74 & 0.427 & 38,185 & 3.63 \\
\hline Winnipeg & 0.419 & 10,930 & 1.65 & 0.319 & 11,440 & 1.73 \\
\hline Total & & 937,180 & & & 545,595 & \\
\hline \multirow[t]{2}{*}{ All Canada } & & $1,029,395$ & 3.47 & & 662,210 & 2.23 \\
\hline & & South Asians & & & Filipinos & \\
\hline Montreal & 0.640 & 57,935 & 1.71 & 0.743 & 17,890 & 0.53 \\
\hline Toronto & 0.449 & 473,805 & 10.19 & 0.404 & 133,680 & 2.88 \\
\hline Vancouver & 0.528 & 164,360 & 8.35 & 0.378 & 57,025 & 2.90 \\
\hline Calgary & 0.466 & 36,855 & 3.91 & 0.417 & 16,380 & 1.74 \\
\hline Edmonton & 0.494 & 29,065 & 3.14 & 0.414 & 14,170 & 1.53 \\
\hline Ottawa & 0.432 & 22,275 & 2.12 & 0.531 & 5,205 & 0.50 \\
\hline Winnipeg & 0.475 & 12,285 & 1.86 & 0.637 & 30,095 & 4.55 \\
\hline Total & & 796,580 & & & 274,445 & \\
\hline All Canada & & 917,075 & 3.09 & & 308575 & 1.04 \\
\hline
\end{tabular}


Table 2: Residential segregation indices for the selected ethnic groups in the large metropolitan areas of Canada, 1981-2001.

\begin{tabular}{|c|c|c|c|c|c|}
\hline & 1981 & 1986 & 1991 & 1996 & 2001 \\
\hline & \multicolumn{5}{|c|}{ Chinese } \\
\hline Montreal & 0.591 & 0.599 & 0.564 & 0.542 & 0.528 \\
\hline Toronto & 0.434 & 0.470 & 0.479 & 0.524 & 0.531 \\
\hline Vancouver & 0.468 & 0.487 & 0.451 & 0.493 & 0.500 \\
\hline Calgary & n.a. & 0.335 & 0.365 & 0.383 & 0.375 \\
\hline Edmonton & n.a. & 0.390 & 0.389 & 0.398 & 0.439 \\
\hline Ottawa & n.a. & 0.446 & 0.442 & 0.439 & 0.428 \\
\hline \multirow[t]{2}{*}{ Winnipeg } & n.a. & 0.461 & 0.456 & 0.453 & 0.419 \\
\hline & \multicolumn{5}{|c|}{ South Asian } \\
\hline Montreal & 0.575 & 0.624 & 0.667 & 0.632 & 0.640 \\
\hline Toronto & 0.390 & 0.428 & 0.416 & 0.432 & 0.449 \\
\hline Vancouver & 0.367 & 0.402 & 0.450 & 0.489 & 0.528 \\
\hline Calgary & n.a. & 0.405 & 0.438 & 0.447 & 0.466 \\
\hline Edmonton & n.a. & 0.500 & 0.489 & 0.507 & 0.494 \\
\hline Ottawa & n.a. & 0.488 & 0.477 & 0.437 & 0.432 \\
\hline \multirow[t]{2}{*}{ Winnipeg } & n.a. & 0.508 & 0.522 & 0.489 & 0.475 \\
\hline & \multicolumn{5}{|c|}{ Blacks } \\
\hline Montreal & 0.456 & 0.519 & 0.517 & 0.470 & 0.460 \\
\hline Toronto & 0.364 & 0.414 & 0.412 & 0.388 & 0.397 \\
\hline Vancouver & 0.332 & 0.437 & 0.448 & 0.311 & 0.328 \\
\hline Calgary & n.a. & 0.410 & 0.439 & 0.332 & 0.337 \\
\hline Edmonton & n.a. & 0.425 & 0.424 & 0.353 & 0.365 \\
\hline Ottawa & n.a. & 0.443 & 0.451 & 0.444 & 0.427 \\
\hline Winnipeg & n.a. & 0.385 & 0.408 & 0.293 & 0.319 \\
\hline
\end{tabular}

Filipinos

$\begin{array}{llllll}\text { Montreal } & \text { n.a. } & \text { n.a. } & \text { n.a. } & 0.720 & 0.743 \\ \text { Toronto } & \text { n.a. } & \text { n.a. } & \text { n.a. } & 0.395 & 0.404 \\ \text { Vancouver } & \text { n.a. } & \text { n.a. } & \text { n.a. } & 0.323 & 0.378 \\ \text { Calgary } & \text { n.a. } & \text { n.a. } & \text { n.a. } & 0.396 & 0.417 \\ \text { Edmonton } & \text { n.a. } & \text { n.a. } & \text { n.a. } & 0.450 & 0.414 \\ \text { Ottawa } & \text { n.a. } & \text { n.a. } & \text { n.a. } & 0.546 & 0.531 \\ \text { Winnipeg } & \text { n.a. } & \text { n.a. } & \text { n.a. } & 0.598 & 0.637\end{array}$

Note: 1981, 1986 and 1991 indices based on single response. 1996 and 2001 based on single and multiple responses. 
Table 3: Percentage of ethnic group $15+$ with a university degree in the largest metropolitan areas of Canada-2001.

$\begin{array}{lrrrrr} & \text { Chinese } & \begin{array}{r}\text { South } \\ \text { Asians }\end{array} & \text { Blacks } & \text { Filipinos } & \text { All Groups } \\ \text { Montreal } & 27.4 & 20.9 & 11.9 & 27.7 & 17.7 \\ \text { Toronto } & 28.8 & 27.1 & 9.2 & 32.2 & 22.9 \\ \text { Vancouver } & 24.3 & 17.4 & 15.9 & 33.8 & 20.7 \\ \text { Calgary } & 24.2 & 26.0 & 10.9 & 30.9 & 21.1 \\ \text { Edmonton } & 23.2 & 28.0 & 10.5 & 30.7 & 16.1 \\ \text { Ottawa } & 45.7 & 50.1 & 13.2 & 33.5 & 16.9 \\ \text { Winnipeg } & 26.3 & 29.0 & 12.2 & 17.0 & 15.4 \\ \text { All Canada } & 27.3 & 25.6 & 12.7 & 30.6 & \end{array}$

Table 4: Percentage of ethnic group 15+ in management occupations in the largest metropolitan areas of Canada-2001.

$\begin{array}{llll}\text { Chinese } & \begin{array}{l}\text { South } \\ \text { Asians }\end{array} & \text { Blacks Filipinos All Groups }\end{array}$

Managerial

$\begin{array}{lrrrrr}\text { Montreal } & 11.4 & 8.6 & 6.0 & 1.9 & 10.9 \\ \text { Toronto } & 11.5 & 9.3 & 7.0 & 5.6 & 13.0 \\ \text { Vancouver } & 12.5 & 7.7 & 8.5 & 5.0 & 11.9 \\ \text { Calgary } & 8.9 & 10.1 & 8.8 & 3.6 & 12.1 \\ \text { Edmonton } & 8.6 & 10.1 & 5.9 & 4.8 & 10.4 \\ \text { Ottawa } & 9.0 & 11.0 & 4.9 & 5.4 & 12.9 \\ \text { Winnipeg } & 8.9 & 8.3 & 7.0 & 2.2 & 9.5 \\ & & & & & 10.4 \\ \text { All Canada } & 11.8 & 9.1 & 5.7 & 4.6 & \end{array}$




\section{7}

Table 5: Average employment income in 2000 of persons 15 and over employed full-time by ethnic group and gender.

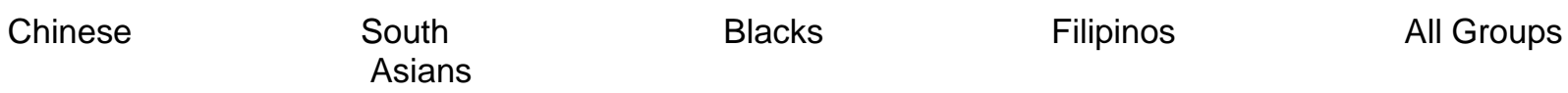

Income \$ Ratio to city Income \$ Ratio to city Income \$Ratio to city Income \$ Ratio to city Income \$ average average average average

\begin{tabular}{llllllllll} 
& & & \multicolumn{7}{c}{ Males } \\
Montreal & 35,641 & 0.75 & 36,043 & 0.76 & 32,131 & 0.68 & 28,458 & 0.60 & 47,337 \\
Toronto & 47,604 & 0.81 & 43,620 & 0.74 & 38,885 & 0.66 & 38,970 & 0.66 & 58,789 \\
Vancouver & 42,160 & 0.79 & 39,881 & 0.75 & 40,489 & 0.76 & 34,813 & 0.66 & 53,095 \\
Calgary & 46,967 & 0.82 & 45,625 & 0.79 & 39,789 & 0.69 & 35,372 & 0.61 & 57,520 \\
Edmonton & 43,196 & 0.86 & 42,641 & 0.85 & 38,301 & 0.76 & 34,554 & 0.69 & 50,158 \\
Ottawa & 58,411 & 1.04 & 59,839 & 1.06 & 39,687 & 0.70 & 42,396 & 0.75 & 56,405 \\
Winnipeg & 39,673 & 0.89 & 41,594 & 0.94 & 37,066 & 0.83 & 29,267 & 0.66 & 44,455 \\
& & & & & & & & & \\
Canada & 45,379 & 0.92 & 44,197 & 0.9 & 38,381 & 0.78 & 36,623 & 0.74 & 49,224 \\
& & & & & & & & & \\
& & & & & & & & & \\
Montreal & 29,443 & 0.86 & 25,963 & 0.76 & 26,716 & 0.76 & 24,360 & 0.71 & 34,353 \\
Toronto & 37,373 & 0.91 & 32,744 & 0.8 & 32,742 & 0.80 & 31,548 & 0.77 & 40,984 \\
Vancouver & 33,289 & 0.87 & 29,970 & 0.79 & 35,460 & 0.93 & 30,882 & 0.81 & 38,118 \\
Calgary & 32,808 & 0.88 & 30,271 & 0.81 & 29,705 & 0.79 & 26,908 & 0.72 & 37,410 \\
Edmonton & 30,731 & 0.91 & 28,794 & 1 & 29,190 & 0.87 & 25,660 & 0.76 & 33,640 \\
Ottawa & 43,094 & 1.01 & 43,163 & 1.02 & 33,005 & 1.02 & 29,262 & 0.69 & 42,507 \\
Winnipeg & 27,217 & 0.85 & 28,240 & 0.88 & 27,134 & 0.84 & 23,994 & 0.75 & 32,209 \\
& & & & & & & & & \\
Canada & 35,040 & 1.00 & 31,899 & 0.91 & 31,358 & 0.90 & 29,768 & 0.85 & 34,892
\end{tabular}

